\title{
Transport Security in the Sustainable Development of the City: Legal Aspect
}

\author{
Denis V. Iroshnikov* \\ Russian University of Transport, Obraztsova Str., 9, build. 9, 127994 Moscow, Russia
}

\begin{abstract}
A sustainable city imposes stringent requirements on transport infrastructure. Nowadays the city transport must meet a number of criteria. That means it has to be advanced, environmentally compliant, and safe. Herewith, transport must be safe for a driver and his passengers as well as for other road users (such as pedestrians and others). Recently, alternative modes of transport have become widespread in the cities. This includes personal electric transport: segway, self-balancing scooter, electric scooter, unicycle, etc). Some countries have been already operating autonomous vehicles within the urban traffic whereas in other countries they are undergoing final testing before their release on urban roads. In large cities and metropolises, carsharing service which has already proven its effectiveness is actively developing. The usual modes of city transport are also improving. For instance, the taxi has been almost completely brought under the control of web-aggregators ("Uber" and others). All of that requires thorough scientific research in the sphere of ensuring transport security which is the indispensable condition of the sustainable city concept.
\end{abstract}

\section{Introduction}

The concept of a sustainable city as one of the most important courses of development includes the transport component. The European urban charter (Strasbourg, 2008) contains provisions on security on public roads as the basis of sustainable mobility. Nowadays the city transport is developing immensely in almost all cities of the world.

There are two directions for the development of transport: 1) introduction of breakthrough means of transport that have never been used before into the urban space; 2) change of the treatment of the existing transport resulting in offering new transport services to citizens (for example, carsharing). What is more, this transport development concerns both personal and passenger transport.

The legal regulation does not always keep pace with the onrush of transport, and the operation of new means of transport (or operation of usual transport in a new way) quite often appears to be beyond legal boundaries. Herewith, one of the main requirements for the city transport is its safety for the user of the given vehicle (a driver, a passenger) as well as for other road users. In this respect, it is necessary to conduct detailed research of emergent modes of the city transport and new approaches to the usual vehicles seen as new

* Corresponding author: dv-iroshnikov@mail.ru 
security challenges in the life of the man and the society. This modern course of transport development of a sustainable city requires correspondingly new legal arrangements of ensuring the security of road users.

It is supposed to consider the following aspects of the city transport development in terms of the legal groundwork for transport security that have determined the structure of the article:

\subsection{Autonomous vehicles}

A growing number of vehicles are becoming equipped with various driver assistance technologies. The introduction of autonomous transport has got a variety of objective reasons. Mainstreaming of these vehicles leads to the increase of highway vehicle capability [1], it provides more transportation accessibility including people with disabilities. Deployment of AVs will also result in economic benefits for companies that can reduce personnel costs [2]. In addition, Japanese scientists point to the reduction of driving stress and emotional spending for private car users [3].

However, the issues of security in cases of using AVs appear to be rather ambiguous. On the one hand, it is commonly accepted that autonomous vehicles are safer since their operation excludes the human factor [4]. But in fact, the situation is not so clear-cut and some researches reveal conflicting points of view on the issue of autonomous vehicles' security [5]. Herewith the security issue of all road users including pedestrians arises.

\subsection{Taxi and carsharing}

At present carsharing is gaining popularity in large cities and metropolises. However, the legal basis for this kind of auto rental service (including the issues of ensuring the security of a drive) is often determined ambiguously.

Certain legal problems also exist in the sphere of ensuring security when using taxicabs through web-aggregators including mobile applications. It is connected with the fact that it allows taxi companies to avoid responsibility for their passengers' security.

\subsection{Personal electric transport}

In recent years, such means of transport as segway, self-balancing scooter, electric scooter, unicycle, and others are confidently coming into the Russian and global markets. In Russia as well as in other countries, the legal status of personal electric transport is defined quite ambiguously. So, this fact cannot but influence the issues of security when using such means of transport. A number of road traffic accidents have already been registered and judicial practice on these cases is substantially different.

\section{Materials and Methods}

The systematic approach allowed scrutinizing the system of legal regulation in the sphere of ensuring transport security with the development of city transport. The authors also applied such methods as analysis, synthesis, induction, deduction as well as scientific modelling which allowed considering the model of the legal groundwork of transport security provision in a smart city.

An essential methodological aspect in considering personal and public security issues is the necessity to implement the pragmatic function of science as security provision presumes early detection, analysis, and assessment of security threats. Within the framework of the 
given research, the authors speculated about possible loopholes in the current legislation, which may become a threat to the road users' security.

The distinctive feature of the methodological approach applied in the article is the combination of the study of current statutory provisions, other researchers' standpoints to the matter, and practical application of legal norms by judicial authorities. On the basis of this investigation, the given methodological approach has allowed summarizing existing problems and suggesting legal developments in the current Russian legislation.

\section{Results and Discussion}

\subsection{Autonomous vehicles}

It is worth drawing attention to certain areas of concern related to the use of autonomous vehicles that must be solved by legal means.

Weather conditions challenge. The researches point out the fact that many automatic systems and sensors that ensure autonomous driving mode operate properly only under optimal weather conditions or during daylight hours [6] (Bartuska, 2020). It is also said that most part of test drives is conducted in sunny weather that is far from reality [7]. A special concern is raised around this issue in Russia since its road and the climatic environment is characterized by extended periods of negative temperatures (up to 8-10 months per year); significant pollutions of road pavement, significant road unevenness causing accidents, and so on [8].

One can imagine such weather conditions (hurricane, tropical downpour, hail, blizzard) that are extreme for automatic driving. In other words, under these weather conditions the automated technology does not guarantee safe driving (like non-flying weather in aviation). Hence, a legal problem arises. It is necessary to regulate extreme weather conditions in certification for a vehicle.

It is generally accepted that in case of emergence the driver must intervene in the process in order to avoid an accident as well as he or she must not sleep or watch videos during the vehicle movement [9]. Thus, the final decision about accident prevention remains with the human. At the same time in case of the emergency existing autonomous braking system and lane-keeping control take over vehicle control from a human. This discrepancy arises the following question: who is to take the decision in case of emergency - is it a driver or a computer? This dilemma between humans and automation raises also the issue of liability.

3. The driver's qualification. It is known that any advanced system which facilitates driving involves loss of driver qualification that may be revealed in a stressful situation. Moreover, scientists emphasize that driving vehicles with a high level of automation appear to be tedious in the long run which reduces situation awareness, and it may intensify the driver's drowsiness [10].

In this case introduction of a special driver's licence is possible. It is also important to issue a legal norm on the requirement to pass regular driving tests.

4. Liability for a road traffic offence. In practice, it may happen that an automated driving system fails to recognize a road sign behind the leaves or another vehicle, or because the sign is covered with the snow or for the reason of existing time restrictions including passing a road traffic accident. This poses the question of liability for a road traffic offence that takes place in the self-driving mode.

5. Unhampered information exchange. Data protection appears to be one of the most significant aspects of dealing with AV operation. This refers, firstly, to data confidentiality 
which disclosure threatens privacy and leads to the necessity of their protection. Secondly, it implies the threat of cyber-attacks including terrorist ones on data.

We would like to touch on the legal aspect of data exchange which fosters the secure environment when operating autonomous vehicles. According to researches' opinion, the following objectives should be addressed: informing the nearest service stations or emergency response services about impairment and related road traffic accidents; collection of statistical data on the most frequent causes of failure of technical equipment [11]. For the purpose of ensuring transport security when operating autonomous vehicles, it is necessary to create a transparent legal environment for unhampered information exchange regardless of national legislation, vehicle manufacturer, point of use, and other indicators.

6. The issues of criminal liability if there are road traffic accidents that have led to people's injuries or death. When an autonomous vehicle is controlled by a human (inside the vehicle or in the remote mode) he or she is liable to take definite actions in case of emergency (for example, to apply the emergency brake and so on). From a legal perspective, this person cannot be regarded as a driver since the latter is a person who operates a vehicle. Actually, the driving process is performed by a computer (machine intelligence). The human's role consists in the necessity to intervene at risk of an accident. Therefore, in cases when such a supervisor makes a mistake, he or she cannot bear responsibility as a driver.

\subsection{Taxi and carsharing}

There are certain legal problems of ensuring security when using taxicabs through webaggregators and mobile applications (such as "Uber", "Yandex-taxi" and others).

A "traditional" company possessing its own fleet and drivers and providing taxicab services is obliged to ensure the necessary level of security of its passengers. Firstly, it consists in inspection of technical state of the fleet and, secondly, in medical inspection of drivers.

Mass transition of taxicabs to online cab aggregators makes it possible for companies to avoid security issues since they provide purely information services [12]. Employed independent drivers with their own transport are not obliged to undergo medical inspection and technical vehicle inspection [13].

This problem requires immediate legal decisions aimed at raising responsibility of webaggregators for security of taxicab services.

Another problem is personal security when using carsharing services that are becoming more and more popular in large cities.

In Russia the contract concluded with carsharing service consumers cannot be referred to any contract established by civil legislation (car rental agreement, passenger transport contract, etc) [14]. In other words, it is a landmark contract which does not imply any legal regulation of its special features.

In these contracts companies envisage special reference to the fact that consumer legislation cannot be applied to them [15].

Besides these contracts do not contain any liability on the part of the sharing service companies to monitor equipment performance and safety in the use of their fleet.

Thus, the disputable legal nature of carsharing contracts does not make it possible to tell about direct responsibility of a lessor to ensure safe riding when leasing a vehicle in a serviceable condition and to provide regular technical condition monitoring.

The problem of responsibility for the technical condition of a vehicle will escalate when car rental firms start leasing autonomous vehicles. It is generally accepted that introduction of autonomous vehicles is a significant advantage for carsharing [16]. 
Herewith, as compared to a usual car, an autonomous vehicle is considerably more complicated in terms of equipment. This involves systems of immense complexity that ensure autonomous driving and disengaging the system directly affects the safety of traffic. Corresponding responsibility for regular technical condition monitoring must rest with the carsharing company.

\subsection{Personal electric transport}

At present, the legal status of personal electric transport is defined quite ambiguously in Russia. In current traffic regulations, these vehicles are not referred to any particular kind of transport intentionally.

According to the researchers' opinion, electric mobility vehicles endow their user with intermediate status between pedestrians and vehicles [17].

Mass adoption of this kind of transport makes countries pass new legal norms aimed at regulating this process. Herewith, different countries address the given issue in different ways and worldwide practice has not been established yet.

The main problem is the legal status of a driver of such transport who can be considered a pedestrian, a bicycle or a moped rider. This implies designated area of use as well as the problem of responsibility for road traffic accidents with the involvement of this transport.

The results of the research have shown that the judicial practice established in Russia to date, is quite ambiguous. Some courts identify electric scooters as a vehicle (usually as a moped) and the person who uses it as a driver of the vehicle. The others on the contrary do not consider these means of transport to be vehicles.

\section{Conclusions}

The conducted research has allowed concluding that it is necessary to improve legislation that regulates performance of the city transport related to its safety towards road users.

A smart city is supposed to be safe and transport which is developing together with the city must also match security criteria. The legal framework should develop operatively and keep pace with the emergence of new means of transport on urban roads. Only in this way it is possible to ensure transport security of the smart city.

Concerning autonomous vehicles the main legal issues are the issues of relationships between the man and the computer including legal liability of the driver in different situations as well as issues of information exchange and its security.

As for the taxi it is necessary to enshrine the responsibility of web-aggregator for the security of a provided service thereby withdrawing them from purely information field.

Similar legal problems can also be observed in the carsharing industry since the legal status of this kind of contract is not enshrined in legislation and accordingly a company does not guarantee safe riding. These companies must be in charge of regular (more frequent that for personal vehicles) monitoring equipment performance of their fleet.

Personal electric transport has a number of problems related to legal regulation that are not controlled by the current Russian legislation at all. It seems appropriate to solve this problem in the following way.

First and foremost, it is necessary to define the legal status of a driver of this kind of transport. For this purpose one can proceed from electric motor power. A person operating a less powerful vehicle may be considered a pedestrian whereas those operating a more powerful vehicle will have a status of a bicycle or a moped rider. Consequently, it will influence the issue of allowable use of this transport as well as the issues of liability. 


\section{Acknowledgements}

The article was published with the support of the RFBR grant No. 19-011-00658 "Transport Security: Theoretical and Legal Foundations, Administrative Law and Criminal Law Means of Security Provision in the Russian Federation"

\section{References}

1. M.M. Morando, Q. Tian, L.T. Truong, H.L. Vu, Journal of Advanced Transportation, 1 (2018)

2. M.E. López-Lambas, A. Alonso, Sustainability, 11, 4986 (2019)

3. R. Abe, Transportation Research Part A: Policy and Practice, 126, 94 (2019)

4. M. Ryan, Science and Engineering Ethics, 26, 1185 (2019)

5. V.D. Pyrialakou, C. Gkartzonikas., J.D. Gatlin, K. Gkritza, Journal of Safety Research, 72, 249 (2020)

6. L. Bartuska, R. Labudzki, Transportation Research Procedia, 44, 356 (2020)

7. K. Rehrl, C. Zankl, European Transport Research Review, 10, 11 (2018)

8. S.E. Buznikov, A.M. Saikin, D.S., Elkin, V. O. Strukov, International Journal of Engineering and Advanced Technology (IJEAT), 8, 5302 (2019)

9. D. Lee, D.J. Hess, Transportation Research Part A: Policy and Practice, 136, 85 (2020)

10. E. Aria, J. Olstam, C. Schwietering, Transportation Research Procedia, 15, 761 (2016)

11. I. Makarova, E. Mukhametdinov, E. Tsybunov, Transportation Research Procedia, 36, 465 (2018)

12. T.E. Mel'nikova, S.E. Mel'nikov, A.O. Borovkov, Vestnik MADI, 1, 107 (2018)

13. O.V. Garina, Managing of Activities to Ensure Road Safety: State, Problems, Ways of Improvement, 1, 131 (2019)

14. I.Z. Aiusheeva, Courier of the Kutafin Moscow State Law University (MSAL), 2, 25 (2019)

15. T.A. Bubnovskaya, Yu. B. Suvorov, Jurist, 7, 32 (2018)

16. C. Pakusch, G. Stevens, A. Boden, P. Bossauer, Sustainability, 10, 2404 (2018)

17. D. Jiménez, Y. Fuente, J. Hernández-Galán, Studies in Health Technology and Informatics, 256, 360 (2018) 